\title{
Examining the Idea of the 'Vulnerable Student' to Assess the Implications for Academic Freedom
}

\author{
Stuart Waiton
}

check for

updates

Citation: Waiton, S. Examining the Idea of the 'Vulnerable Student' to Assess the Implications for Academic Freedom. Societies 2021, 11, 88. https://doi.org/10.3390/soc11030088

Academic Editor: Gregor Wolbring

Received: 21 June 2021

Accepted: 16 July 2021

Published: 31 July 2021

Publisher's Note: MDPI stays neutral with regard to jurisdictional claims in published maps and institutional affiliations.

Copyright: (C) 2021 by the author Licensee MDPI, Basel, Switzerland. This article is an open access article distributed under the terms and conditions of the Creative Commons Attribution (CC BY) license (https:// creativecommons.org/licenses/by/ $4.0 /)$.
School of Business, Law and Social Science, Sociology Division, Abertay University, Dundee DD1 1HG, UK; s.waiton@abertay.ac.uk

\begin{abstract}
This paper analyses the concept of vulnerability as it is applied to university students, and also staff, to assess the extent to which it has become a new norm that transforms the understanding of the individual — from being more robust, towards a more fragile sense of personhood. We examine the changing use of the term 'vulnerable' over time and with reference to the institutionalisation of the 'vulnerable subject'. The paper relates this to the theoretical discussion about postmodernism and the 'end of truth' within academia, with the subsequent emergence of safe spaces as a mechanism for protecting the vulnerable student. Using snowball sampling, a pilot ethnographic study of academics who have experienced, or claim to have experienced, limits on their academic freedom is developed. One conclusion is that limits to academic freedom stem from within the academy itself. This conclusion is related to the growing understanding that student 'wellbeing' necessitates the regulation and 'policing' of knowledge and ideas that are deemed to be offensive to the vulnerable student.
\end{abstract}

Keywords: vulnerability; academic freedom; freedom of speech; prevent strategy; liberalism; safe space

\section{Introduction}

The question of academic freedom and the wider issue of freedom of speech and the need to limit speech, indeed, at times, to criminalise it, has developed as an area of interest and concern over the last decade both within educational theory and academia more generally [1-3]. Indeed, concerns that universities are becoming institutions prone to limit rather than expand ideas led the UK education secretary, Gavin Williamson, to promote the need for students to be exposed to, rather than protected from, "outlandish, provocative or uncomfortable ideas" [4]. Indeed, such are the concerns about academic freedom that the British government plans for a 'free speech champion' to regulate England's campuses.

In the past, key concerns about academic freedom related to external pressure from conservative groups, churches and governments or to economic pressure-something that led to the American Association of University Professors writing the 1915 Declaration of Principles, regarding the principles on academic freedom and tenure (see Appendix A). By contrast, today it appears that most forms of pressure that limit academic freedom come from within the university; from practices and processes developed to support the "student experience" and protect student wellbeing. A recent Civitas report [5], for example, found that 86 percent of British universities faced either severe or moderate free speech restriction. Key to most of the restrictions were policies, practices and forms of activism within the academy itself.

The Civitas report argues that today most of the measures that limit academic freedom come in the form of, e.g., free speech policies that actually limit speech; from what is described as a form of "cancel culture"; internal incidents of regulations related to particularly sensitive issues like that of "transphobia"; and university policies around bullying and harassment, where "personal offence", for example, is claimed by a staff member or student. Where there is external pressure on British universities this, it is argued, comes 
largely in the form of online "activism" and "shaming" via social media, rather than from traditional and conservative institutions.

With regard to the discussion about perceived differences in the approach taken by Russell Group universities and post-1992 universities-where the latter are seen as being potentially more restrictive [6] — the Civitas report found that there was little difference between these university sectors in terms of levels of restrictions on academic freedom, with Oxbridge universities being among the most restrictive within the UK.

Within sociology, a key reason for the trend towards regulating academic freedom and freedom of speech relates to the cultural and political relegation of freedom as a "first order principle" in comparison to that of safety [7]. Safety, it is argued, has become a new moral absolute that constantly expands its remit and incorporates the idea of "psychological safety", where words themselves are understood as a form of "harm". When it comes to the contestation between freedom and safety, Frank Furedi argues, the "securitisation of freedom" means that "freedom needs to be regulated to minimize attendant risks and harms".

Within legal theory we find that for over three decades, concerns have been raised about the expanding meaning of harm, something that is understood to have developed most significantly since the late 1980s [8]. This elevation of harm, Furedi argues, is interconnected with what he calls a "therapeutic culture" $[9,10]$. For Ecclestone, this elevation of harm within a therapeutic culture, and within education, places an emphasis upon "emotional harm" and risks, placing safety ahead of freedom with regard to academic practices [11].

One way to think about this development is to examine the way in which the idea of 'vulnerability' has expanded as a category through which we understand not only the nature of specific 'vulnerable groups' but, more generally, how the idea of the 'vulnerable subject' has become a more universal framework for understanding the human condition [12].

Studies of student vulnerabilities are often engaged with through a psychological lens and, to some extent, are taken at face value where, for example, stress levels of students are studied in and of themselves to better understand the student experience [13]. In this paper, we take a sociological approach that addresses the idea of student vulnerability as part of a cultural script, or a culturally constructed discourse within the therapeutic culture. Once established as a norm, in contradistinction to the robust liberal subject, or indeed to government minister's pronouncements, the trend within universities is to understand students as primarily vulnerable subjects who need 'safe spaces', to protected them from certain ideas and to protect their emotional wellbeing [14].

\section{Materials and Methods}

Below we will examine some of the wider themes associated with the challenge to academic freedom, the diminishing valorisation of the pursuit of truth, the elevation of vulnerability as an ontological category and the infantilisation of university life. This will be followed by a short case study.

The study attempts to give further and more detailed examples of the restrictions that some lecturers feel regarding academic freedom. This is done to gather some qualitative data, using a snowball sampling method to develop a brief ethnography of academic life. Lecturers who had previously raised concerns about academic freedom were interviewed. As part of the interview process a request was made for names of other academics who might be interested in discussing issues they had faced regarding academic autonomy and freedom within their institutions. This stretched the framework of the theme of academic freedom into unfamiliar universities and issues not previously considered. It also provided further evidence of issues associated with vulnerability. In interviews carried out online or in telephone conversations, questions were raised about academic freedom, but also more general questions were raised with regard to issues or restrictions that were experienced within the academic environment. Occasionally, past discussions were re-raised here, 
where prior knowledge of issues of relevance existed. Some of those interviewed had what could be described as a trusting relationship with the interviewer that allowed a more full and open discussion. As such, these interviews do not give a cross section of the academic community nor do they represent a balance of experiences. Rather, through the gathering of some in-depth qualitative data, aspects of the academic culture were explored to help examine the way certain 'insider' concerns are experienced and expressed. The experiences discussed were both personal to those interviewed and related to colleagues of these participants who had also experienced certain difficulties in their work. Some of the names and details about the participants have been changed to ensure anonymity.

The small sample size should be seen as limited, in terms of the capacity to generalise from these interviews and should be viewed more as a trial or pilot project that will hopefully allow for further examination in the future. Ideally, with snowball sampling, as Heckathorn notes, over time the chain of connections between the researcher and participant will become so distant that the participants become increasingly random and independent of the researcher [15]. This was already beginning to occur with this research but would need to be extended in the future. As it stands, the bias of the research remains because the majority who participated were 'cooperative subjects', or subjects whose perspectives fit, to some degree, with those of the researcher.

Through the interview process, themes regarding academic freedom were drawn out and are discussed below with reference to controversial subject matter, day-to-day restrictions and what we could categorise as a form of 'low level cultural filtering' through which academics come to self-censor, or perhaps more accurately, develop limits to their academic work and practices.

\section{Themes}

\subsection{Truth?}

Before looking at the theme of harm and vulnerability, it is worth noting that within academia itself, there has been a significant radical critique, often inadvertently, of freedom of speech, generated, in part, by a questioning of the idea of 'pursuit of truth'. This helps, in part, to explain how and why restrictions on academic freedom are often found to be coming from within the academy rather than from external, conservative sources.

Most recently this has been explored by Helen Pluckrose and James Lindsay in their book Cynical Theories: How Universities Made Everything about Race, Gender and Identity [16]. Here they explore aspects of the postmodern turn, particularly post-1990s, with the move away from more abstract and skeptical works by the likes of Michel Foucault and Jean Baudrillard by 'critical' theorist, who developed a form of academic activism that has accelerated the "war against words" [17,18].

Crucially, for us, the importance of the 'loss of belief' in the pursuit of truth, or indeed the representation of the pursuit of truth as a form of power, has helped to undermine the importance attributed to freedom of speech and academic freedom [19]. If all knowledge is a form of power and we need to understand that there are truths, plural, rather than any actual truth, or indeed that there is possible danger in the 'pursuit of truth', then a more relativistic epistemology develops, and the weight and significance given to ideas and the free pursuit of ideas or the open-ended interpretation of them is potentially undermined or diluted [20].

Joanna Williams believes that the challenge to free speech and academic freedom is the outcome of the collapse, or at least the serious decline, of liberalism, Enlightenment ideas, and the belief in knowledge as a search for truth [21]. Previously, for example, with the 1915 Declaration of Principles regarding academic freedom, written by the American Association of Professors, the pursuit of truth within the academy was represented as a normal and expected part of university life (Appendix A). Today, in comparison, Furedi notes, the very idea of 'truth' increasingly sounds pompous and other-worldly, and we are inclined to celebrate 'cultures', rather than to encourage a sense of being 'cultured', with the latter being tarnished with accusations of power and privilege $[9,10]$. 
Critical social theorists, like Herbert Marcuse, in the mid-1960s questioned the value of classical ideas of progress, tolerance and freedom, including freedom of speech. For Marcuse, Enlightenment ideas of 'progress' were understood as being profoundly negative, as being "bound up with intensified unfreedom the domination of man by man". Pressing home his opposition to Enlightenment myths, Marcuse argued that "concentration camps, mass exterminations, world wars, and atom bombs are no 'relapse into barbarism', but the unrepressed implementation of the achievements of modern science, technology, and domination" [22]. In his 'Repressive Tolerance' written in 1965, Marcuse argued that 'tolerance' was a bourgeois oppressive concept, nothing more than an ideology that favoured and fortified the status quo of inequality and discrimination [23].

Other radical thinkers, notes Amy Adler, have challenged the idea of freedom and tolerance and helped to develop the intellectual case for regulating speech. Adler observed that "the feminist anti-pornography movement, led by Catharine MacKinnon, and the anti-'hate speech' school, led by a group of legal scholars ... wish[ed] to prohibit speech that harms historically victimised classes of society". These developments, Adler notes were, "nothing less than a war on traditional First Amendment jurisprudence", and as such were a direct challenge to the idea of academic freedom [24].

In their Manifesto against the Enemies of Modernity, Pluckrose and Lindsay argue that, increasingly, what they call the "progressive left" has aligned itself "not with modernity but with postmodernism, which rejects objective truth as a fantasy dreamed up by naïve and/or arrogantly bigoted Enlightenment thinkers who underestimate the collateral consequences of Modernity's progress" [25]. These "enemies of modernity", they believe, are on the rise and have become increasingly influential within academia.

\subsection{The Rise of Vulnerability}

Part of the story about the 'loss of truth' relates to the loss of politics, or more generally, to the loss of 'grand narratives', to a 'Waste Land' of belief, or to what French political scientist Zaki Laïdi has called A World Without Meaning [26,27]. In a world without meaning, Zygmunt Bauman argues, society loses its direction, and as a result a sense of powerlessness becomes more pervasive [28]. Alongside this confusion of meaning and purpose, Furedi argues, there is a declining sense of social progress and a growing introspection that helps to propagate a wider sense of vulnerability, of people no longer being doers but rather as diminished subjects to whom things are done [29]. Discussing what they call the "diminished subject", Andrew Calcutt and James Heartfield argue that within this political and cultural climate, the idea of human vulnerability, that developed out of the 1960s, has become ever more significant as a prism through which human experiences are understood [30,31].

Using Google Ngrams that allows a search of words and terms in books since 1800, we can see the growing interest in the idea of human vulnerability-beginning at the start of the twentieth century, becoming more significant after the Second World War, but only really taking off at the end of the 1960s. Noticeably, the growing interest and writing about vulnerability emerges at the same time that Marcuse, and others, were developing their ideas, and from this point on we see an exponential rise in the use of the term 'vulnerable individual' (Figure 1) (Appendix B). A similar growth in the use of the term 'vulnerable group' (Figure 2) also emerged at this time. 
Q. vulnerable individual

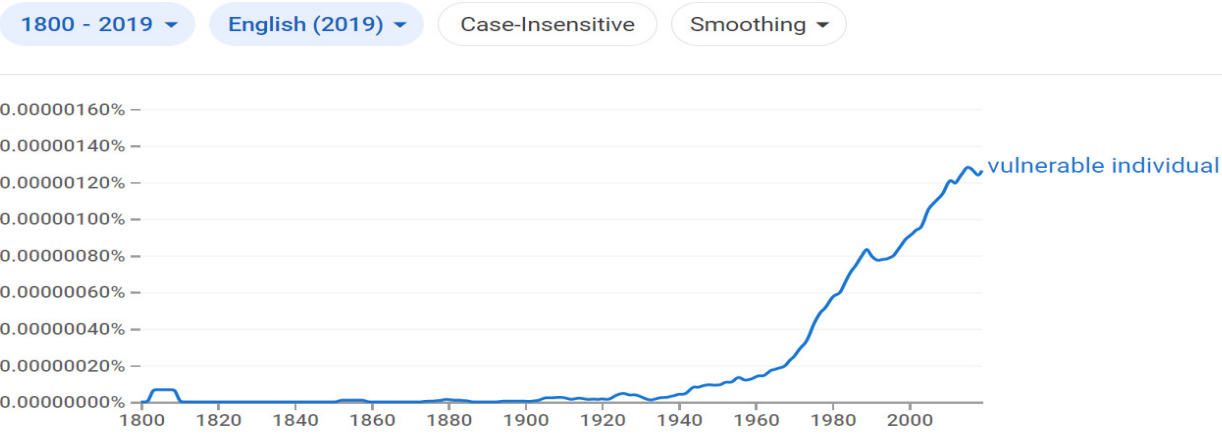

Figure 1. Google Ngram Searching Result of term 'Vulnerable Individual'.

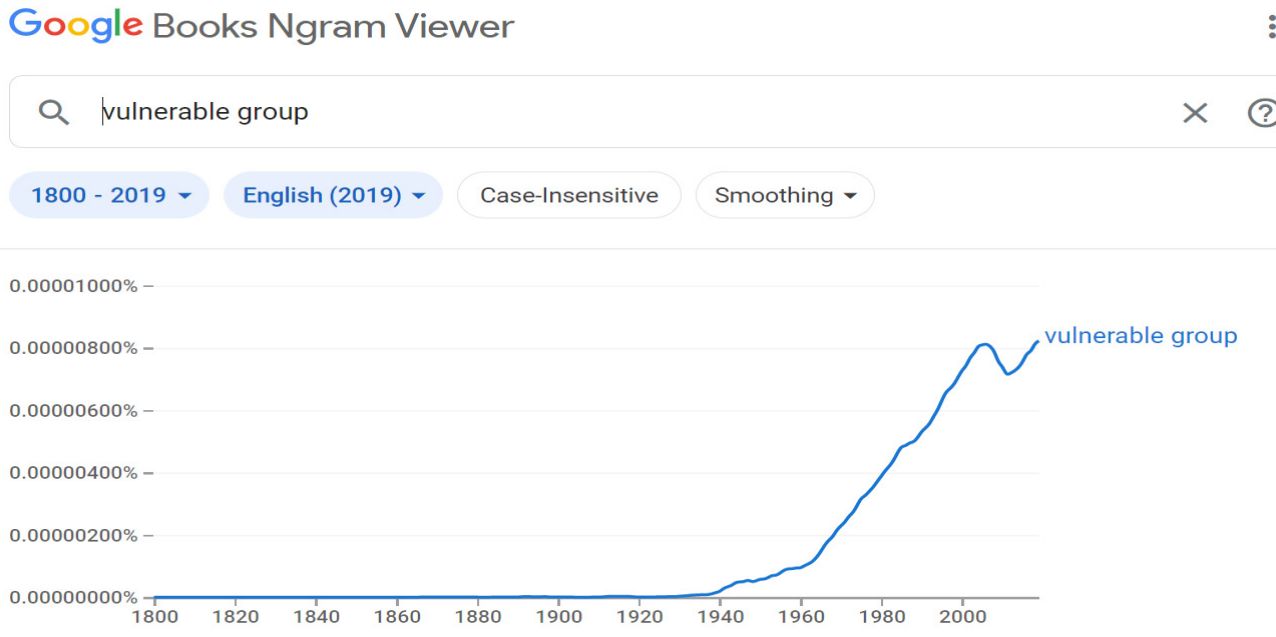

Figure 2. Google Ngram Searching Result of term 'Vulnerable Group'.

A study of the growing idea of human vulnerability concluded that "the term 'vulnerable' is used far more today than at any other time in the last 200 years".

The idea of vulnerability is now used in relation to more issues and experiences; it has also become used to define or label certain sections of society, in particular those sections of society that are understood to have suffered political oppression or other forms of inequality, as well as other groups who are incorporated into this politicised category, like the disabled [12].

Looking at the use of the category of vulnerability within workplaces, local authorities, national and local bureaucracies, social policy, and other areas of life, we can conclude that the idea of the vulnerable person was institutionalised in the 1990s [12] (pp. 4-6).

Through a Google search of institutions and organisations, it is difficult to find a public or professional body that does not have at least one policy or initiative that explains their understanding and capacity to engage with the 'vulnerable' [12] (pp. 4-6). We find, overall, that, increasingly, groups or sections of the population, like children, are uniformly defined through the language of vulnerability, a category that is increasingly being applied to university students and indeed, often with reference to mental wellbeing, to the population more generally.

Looking at the academy, universities have a variety of policies, initiatives and activities that engage with 'vulnerable students'. Often based within a discussion of 'Student Wellbeing,' here we find that vulnerability relates to 'academic, personal or practical issues'. 
Some universities have their own dedicated officers and specific email systems for the vulnerable. The National Union of Students has a variety of reports and initiatives that discuss vulnerability in a variety of contexts-including religious beliefs, where religious students, as a minority, are discussed as being vulnerable, students are described as being vulnerable to crime, to gambling, in relation to a living wage campaign, to housing, and to drugs and educational funding, where poorer students in particular are described as being 'vulnerable' [32,33].

In 2018, the National Union of Students (NUS) announced a partnership with Gambanan app that helps users block access to online gambling. Here the claim was made that one-in-eight undergraduates had missed lectures or seminars because of gambling. The report explained that "many of these students are amongst the most vulnerable-and gambling addiction can be both a cause of and trigger for further mental health issues" [34]. More action was "desperately" needed to protect students from betting companies who were "preying on student vulnerabilities".

Even when looking at the government's anti-terrorism Prevent Strategy, that is described by the staff union UCU as a threat to academic freedom, we find that students who are understood to be potential terrorists are described as being "vulnerable to radicalization", as "vulnerable individuals" or "vulnerable people" who are "drawn into terrorism" [35]. Reading the Revised Prevent duty guidance: for Scotland, even the act of becoming a terrorist is understood through the prism of vulnerability—of being 'done to', as Furedi would say [36].

Understanding or being aware of vulnerability has become a form of good practice. For some organisations like the NUS, vulnerability appears to be something of a starting point when relating to and developing services for students or initiating campaigns. For the police, engaging with the wellbeing of vulnerable people has become a "core" purpose [37]. At a number of levels and within a number of institutions, being aware of 'the vulnerable' and developing practices to engage with the vulnerable subject has become their raison d'être. Issues of safety, safeguarding, protection, prevention, and the support necessarily implied through the label of vulnerability, give a regulatory dimension to many of these practices and issues. To be aware, to engage with, and to protect the vulnerable is to be good, per se.

\subsection{The Infantilisation of University Life}

The engagement with students as vulnerable is potentially problematic and risks becoming a discursive framework through which university life is fashioned.

Discussing the Prevent strategy, Bill Durodie argues that an essential part of this strategy is to protect students from "extreme" ideas [38]. The danger, with this approach, he believes, is that it weaponizes ideas and it incentivises a process of student infantilisation. A more passive view of students is institutionalised through this mechanism. This passivity arguably fits comfortably within the wider discussion and engagement with the 'vulnerable student': students need to be kept safe from ideas that 'harm'. It is noticeable that despite significant opposition from lecturers, lecturers' unions and indeed from university management to the Prevent strategy, rarely is this idea of the vulnerable student discussed or seen as problematic. It is also of note that in the Civitas discussion about university regulation of speech, where hundreds of examples are discussed, they found only one case of university censorship related to the Prevent strategy.

More generally, within universities we have seen the emergence of practices that treat students as vulnerable and offer protections to them with regard to ideas [5]. Three of these new practices, or outlooks, have been categorised through the labels of microaggression, trigger warnings and safe spaces. All of these developments, that arguably are dimensions of the vulnerable student, developed first in the United States and are developing within the UK [39].

Trigger warnings are advisory labels given to students to classify certain course material as potentially traumatising. Examples of trigger warnings in the US were first 
noted in the Guardian newspaper in 2014 with reference to warnings given to students about The Great Gatsby. The warning read, "TW: suicide, domestic abuse and graphic violence" [40]. Jeannie Suk Gersen, a Harvard Law professor has written about her concerns that students are being advised not to attend law classes on sexual violence in case it makes them feel uncomfortable [41].

In the UK, university managers and academics are beginning to engage with this form of student protection, seen for example with University College London, where students studying the archaeology of modern conflict were told that they could leave class if they found discussions "disturbing" or "traumatizing" [42]. In 2019, in the UK, the head of the English Department at the University of York apologized to "students who were offended when they came across the word 'negro' in lectures about the work of the African-American sociologist W.E.B. Du Bois" [43].

This approach is strongly endorsed by student union associations in many UK universities. The Oxford University student association, for example, argues that trigger warnings are a positive development that encourage debate because they prevent students from being traumatized and so enable them to take part in that debate [44].

Another development in U.S. universities and one that is being adopted already in the UK is the idea of microaggressions. Promoted as a form of hyper-awareness to the need to regulate language, microaggressions are understood to represent the 'real' meaning behind everyday comments that are made between people. The list of microaggression terms, developed for use in the University of California, Los Angeles, include comments like, "Where are you from?" which implies "You are not a true American," and, "There is only one race, the human race", which is said to be a "denial of the significance of a person's ethnicity" [45]. These terms are said to be a form of racism, regardless of the intention of the person who is speaking, and this topic is now being discussed in the UK in the framework of 'everyday racism', and the student campaign around microaggression in Harvard, for example, quickly spread to Oxford University and is ongoing [46].

The concern about microaggression, like trigger warnings, comes less from university management than from student activists and 'radical' academics. In the UK, some universities are beginning to take a more proactive approach to the issue. Sheffield University, for example, recently advertised posts for 20 paid students to tackle microaggression among the student body. The new recruits' job will be to listen to other student conversations and to intervene when they hear "subtle but offensive comments" and to encourage "healthy conversations" [47].

The idea of a safe space is a place/space where individuals can feel safe, not threatened, by certain types of behaviour, ideas and language with which they are uncomfortable-a place where you have a sense of ontological security. In an early discussion about these spaces, Robert Boostrom describes the safe space as an "emerging metaphor for classroom life" [48]. This paper was noticeably written with reference to school, rather than university students. Interestingly, the paper concluded that this well-intentioned educational idea, "unintentionally undermines critical thinking".

The UK's National Union of Students (NUS) has a 'safe space' policy that is endorsed by many NUS organisations. These policies relate to harassment and intimidation but also argue that students should be free from 'judgement.' Many of the statements relating to safe spaces refer to the feelings of the individual student regarding feeling 'isolated,' feeling uncomfortable', not feeling welcome or simply fearing that this may be the case. Relating to microaggression, the safe space policies discuss 'everyday terms' like 'gay' (meaning bad) which cannot be allowed because they "can also cause offence or reinforce negative stereotypes". At Bristol University, the idea of safe spaces has been incorporated into the student union code of conduct. Within this code, an anti-discrimination and harassment statement has been produced and representatives are encouraged to read it out "at the beginning of all large SU activities". Here the starting point appears to be a presumption of student vulnerability and a need to illustrate the protective nature of the student association where "members are free from fear" [49]. 


\section{The Therapeutic University}

The most comprehensive study of the significance of 'vulnerability' within universities comes in the book by Kathryn Ecclestone and Dennis Hayes entitled, The Dangerous Rise of Therapeutic Education [50]. Here they incorporate an analysis of educational theory with the changing therapeutic practices within universities and the increasing elevation of the idea of vulnerability as a framework for governance and the management of both staff and students. In the chapter The therapeutic university, Ecclestone and Hayes argue that there are four processes that encourage vulnerability within universities: the elevated concerns about the vulnerability of students and staff, the rise of counselling courses, a new therapeutic philosophy of education and the rise of therapeutic teacher training. Additionally, they note that vulnerability takes a specific form within the academy, specific to the perceived emotional risk of dealing with intellectual ideas [50] (p. 86).

Inter-related to these developments, the authors note the increasing infantilisation of students, the presumption that they cannot cope without some form of counselling and a move to think about students in classrooms and tutorials as potentially vulnerable [50] (p. 87).

A new type of 'support' is now offered to students, and within this framework of therapeutic support, education itself-course work, essays and exams-are understood through the prism of "stress". In other words, in part at least, the pursuit of knowledge has been pathologized. Consequently, the expectation of learning and the sense of excitement or striving associated with university life now competes with an institutionalised anxiety about the potentially damaging dimension of learning itself.

Facing criticism and contested ideas, Ecclestone and Hayes note, can now be seen as problematic. Quoting a 'Guide to Students' from counselling services, they note how subjects, like sociology, are seen as potentially stress inducing because they encourage students to "re-examine areas of their lives which have previously seemed unproblematic" [50] (p. 92). Almost any challenge, pressure or even just changes in the lives and learning of students can now be reimagined as psychologically harmful, they argue.

Assisting these developments and this problematised approach to education, they note the increasing development of therapeutic education as a thing in itself, with university courses not only in counselling but also in 'emotional literacy' and 'emotional well-being' that have proliferated over the last two decades. By 2007, they noted that 517 colleges and universities were offering therapy related courses, a development that facilitated the accreditation of specific forms of therapeutic careers and that, more generally, helped to develop a "therapeutic ethos" within universities [50] (p. 94), an ethos that is, again, in part, interconnected to the sense of the student as emotionally constituted and psychologically vulnerability.

Struggling to defend the classical idea of the university as a place specifically for the development of knowledge, enlightenment and the pursuit of truth, Ecclestone and Hayes note that academics like Stephen Rowland, who are attempting to develop a new philosophy of education, also adopt a form of emotionalism. Unable to defend the pursuit of knowledge as a thing in itself, Rowland falls into an alternative form of therapeutics in his defense of "intellectual love" and the "love [of] one's subject" [50] (p. 96). Rowland, they recognise, wants to defend subject based knowledge and the pursuit of truth but feels he can only do this by retreating inwards, into the inner world of emotions (of love) to do so.

The elevation of emotions and emotionalism in universities, they argue, undermines the 'disinterested' nature of academic life that is necessary for the pursuit of truth. What Ecclestone and Hayes are suggesting is that the pursuit of knowledge needs the individual to step outside of themselves, as best they can, to be a public individual rather than a private self, a thinking being rather than an emotional being, someone who stands above an issue and attempts to analyse it dispassionately rather than someone who is not capable of standing outside of themselves and their feelings. Today, the trend is for the inner focused 
perspective to become institutionalised through the various therapeutic process, practices and the shifting ethos within the academy.

Taking all of these developments together, what we end up with is a situation where the important act of skepticism and criticism of any and all ideas can be reinterpreted, from a feelings perspective, as a form of offense, and as hurtful. Consequently, the logic is for universities to encourage the inevitable clash of feelings to be examined and adjudicated through administrative processes and procedures, leading to a situation where disciplinary measures are triggered and used to regulate 'offensive' ideas and issues that emerge within the classroom.

Astutely predicting the therapeutic trends within universities, Ecclestone and Hayes argue that,

"None of these changes has anything positive to contribute to academic life. And they will get a firmer hold on the academy as the new generation of teachertrained lecturers enters the profession influenced by sessions that emphasise the emotional side of working in higher education. Emotions, after all, cannot be questioned: they just are [50] (p. 98)."

One result is that academic freedom is weakened through this prism of vulnerability, due, in part, to the elevated significance given to the subjective feelings of students, or at least, some students. The outcome is the potential for "emotion wars", where the most 'hurt' and 'offended' individuals increasingly come to determine the limits of intellectual engagement.

In the 'Preface to the Classic Edition' of The Dangerous Rise of Therapeutic Education, Kathryn Ecclestone and Dennis Hayes note that the pursuit of knowledge will potentially be undermined through changes within universities that elevate the anxiety about the "psychologically damaging consequences" of knowledge itself. Already, they noted, Buckingham University was being promoted as Britain's first "positive" or "mindful" university. We find that by 2018, Sam Gyimah, the conservative minister for universities, gave an "ultimatum to vice-chancellors on student mental health, warning them it is not good enough to suggest that university is about academic education and nothing else". As Ecclestone and Hayes note, this idea that universities, from the top down, must elevate the importance of mental wellbeing is not simply an add on to the pursuit of knowledge but turns this pursuit of knowledge into a potential problem for 'vulnerable' students. The pursuit of knowledge, they note, within this therapeutic framework, increasingly becomes something that is seen as "oppressive" [50] (p. ix).

\section{Findings}

The nine interviews with lecturers in Scotland and England occurred in the first four months of 2021. The limited number of participants makes this a pilot project that can hopefully be built upon. Initially, three colleagues who I had worked with were contacted. All three were strong advocates of academic freedom and subsequently passed on details of (four) colleagues they thought it would be worth talking to about their experiences regarding academic freedom. From these four additional participants, a further two lecturers were passed on to me, thus developing a snowball sample of nine individuals, all of whom work in the humanities. Covering disciplines from politics and psychology to law and sociology, it is worth noting that it is often lecturers who discuss current social and political issues within their course who have the greatest concerns regarding limits to academic freedom. Due to Covid-19 restrictions these interviews took place via Zoom and through a number of telephone conversations. Consequently, there were some limitations to the interactive and personal nature of one-to-one in person interviews, but these were not felt to have limited the discussions or the nature of the interviews.

Despite some of the interviewees having expressed concerns about academic freedom prior to the interviews, when pushed to discuss the daily routine and experience of university life, most would talk about their work as "generally okay", or even "weirdly fine". The weirdness reflected, in part, to the fact that all lecturers spoken to were aware of the discus- 
sion about restrictions on academic freedom and all but two would see themselves as being strongly in favour of this freedom. Overall, the bulk of the time spent by these academics was not within a framework where the threat to academic freedom was a constant concern.

Psychology lecturer Carol, for example, explained, "I'm fine, more or less happy to cover any topic, as long as I'm well prepared. I think things are worse in the US. Although it's becoming more of a thing, perhaps in general life over here, more than in academia". Similarly, criminologist Christine said she "had not experienced any direct limits," noting that it was, "more low level than that".

For all of the lecturers, even those most concerned about academic freedom, limits to this freedom, at least at the level of teaching, was rarely overt. Stephanie, another psychologist, who taught in the area of mental health explained that she had, "never been told what to teach or what not to teach".

One area where direct, or potentially direct censorship was experienced was with lecturers who taught Chinese students. China have passed a law making it possible for them to arrest anyone in the world who enters China and who is believed to have said something that threatens 'national security'. The potential threat to Chinese students who express opinions while in the UK, and also to UK staff who teach in China, was felt to be considerable.

Paul, who teaches politics to Chinese students, explained that, "British universities have said nothing in relation to academic freedom and tend to want to stop you being too critical of China".

Again, however, this limit was "rarely explicit", more in the form of, "subtle concerns about guest speakers or things being "'too' political". Paul had raised concerns about this with management but explained that, "My university tries to ignore it", but "when you're teaching international relations or politics you don't want the Chinese students to say anything in case they're put at risk". For Paul, the irony was that with all the talk about 'staff wellbeing', when a serious risk of this nature comes along, "lecturers are exposed", concerns raised are "never resolved", and the university is "completely complicit".

\subsection{Controversy}

Despite Carol, Christine and Stephanie all noting that things are 'generally okay' in their day-to-day work, they were also conscious that if the subject was controversial, they either found barriers to their work or felt nervous about how colleagues and management would react.

Christine, for example, who found her job, "weirdly fine", also believed that one of her papers that was challenging aspects of critical race theory was dropped from a special edition of a journal because, "BLM [Black Lives Matter] had just kicked off". She explained that following a conference presentation, she had been encouraged to write the paper, but the editor then explained that they would have to "send it to someone who knows more than we do about the subject! Then I heard nothing, and the journal was published without my paper. I think they were hoping I would just go away. Basically, I think they were saying we're not publishing it because it makes us feel uncomfortable".

For Christine, who talked about 'low level' pressure from her line manager, there was a conservatism regarding political issues, "even issues to do with culture and local councils' economic priorities. If you even debate these critically at all, there's background noise from your boss. They don't say don't do it, but there's definitely a kind of ' $\mathrm{I}$ 'd rather you didn' $\mathrm{t}$ ' vibe to the whole thing".

Law lecturer, James, described the experience of his colleague, Marcus, who had been "ostracised by people in the division who called him racist". Marcus' work questioned the narrative of Islamophobia surrounding a major government initiative. "Once it kicked off, he had three journals refuse to publish his work. People would talk about him behind his back, undermining him. He challenged them on the whole dignity of work policy. Some of the others care about their academic freedom but couldn't give a shit about others. Academic[s] are in their personal silos. Yeah, defend their free speech but not others". 
Carol, who was "more or less happy to cover any topic", also admitted that when it came to potentially controversial topics and how management and even some colleagues would react, she was, "worried how much they would be on your side. Would they back you?" Carol's concern about the "general climate", was elevated by examples she found within the British Psychological Society blog where there was a tendency for people to "pile-on rather than discuss things". With one particular example, she explained that there had been a "massive pile-on, from quite senior academics", against a colleague who "was taking issue with Black Lives Matter". Carol said, "It felt almost cult like," and explained after a pause that, "I'm worried about the direction BPS is going. I found it quite unsettling". Carol was also conscious of the discussion about 'decolonising the curriculum' which wasn't a major concern but was something that meant she felt the possibility of external pressure being used to ensure she adopted certain writers on her course that she would not automatically use. She explained that she was, "unsure what's going to happen" with the decolonisation process and was concerned about "potentially being told to incorporate something [into the curriculum]".

Christopher, a statistics lecturer working in England is another example of someone whose day-to-day work was "fine", but he noted that he was more conscious now about certain topics. "I use examples, on the stats course, of dichotomous variables that divide things into two parts, and I used to use sex as an example. But I've stopped using it in case the trans issue is raised, or they say I'm being coercive, and that's not an argument I want to have". For Christopher, despite his general support for his work and the university, this self-censoring represented, "something quite problematic".

Christopher, discussing his statistics students explained, "I've an email here from a student wanting to know if she can use the ' $\mathrm{N}$ ' word in her dissertation. She's looking at [the band] NWA. I didn't know what to tell her". Criminologist, Christine, noted, "I self-censor a bit with some staff and some students. I'm a bit wary of identity issues".

Architecture lecturer, Alex, felt there were certain issues that were restricted or limited in some form, "like the environment". Alex, whose work questions aspects of environmentalism within architecture, again explained that "it was less about direct restrictions [than] that some of my work is ignored in the division. It's not like there's a barrier but you can tell that nobody wants to discuss it or have a discussion or presentation about it". Within architecture, Alex felt that the professional body, the Royal Institute of British Architects, that oversaw the degree programme, had adopted a certain uncritical approach to environmentalism within the profession and was, "dictating content", and that, "academia does what it's told", by this professional body. Consequently, issues and ideas developed out with academia, in a professional organisation with its own pressures, were potentially limiting certain perspectives on this course.

Malcolm, who occasionally acted as a union representative for lecturers, explained that he'd come across "a few cases where the equalities framework was being used by human resources and management with issues around race and the trans[exual] question". He believed that, "They seem to want to find a reason to limit what lecturers say. They feel obliged under equalities [legislation]". None of the cases discussed by Malcolm had resulted in disciplinary proceedings but these cases took the form of "semi-informal chats". For Malcolm there was a "balancing act for the university" regarding student wellbeing, often seen in relation to the Equalities Act, and academic freedom. "It's definitely a form of pressure," he explained.

\subsection{Low Level Cultural Filtering}

Some of the examples given above involve what lecturers felt was a direct form of limits on speaking or writing, particularly around controversial issues. Most of the concerns, however, were more 'low level' and part of a 'climate' or what psychology lecturer Stephanie described as a form of "cultural filtering".

Stephanie was conscious of certain issues of controversy but was also, due in part to her mental health teaching, sensitive to the 'wellbeing framework' that encouraged what 
she called a form of "cultural filtering" of work within the academy. Stephanie said, "I'm glad I'm not on Twitter because of the trans stuff. It's a dark place." Regarding academic work she noted that, "It's more self-censoring. It's not specific, more a kind of culture. I don't want to get on the wrong side of the student body or the uni[versity]'s corporate message".

The corporate message, for Stephanie, incorporated a range of 'consumer' issues that overlapped and were part of the equality framework. This can be synthetised with the expression "need to look after student wellbeing". "We've moved from guidance of knowledge to wellbeing monitors," she explained. "I've never been told, but with all the emails about it and the idea of not damaging the wellbeing of all student. How can you know everything that can set someone off? It's like we're guardians of their wellbeing. I don't do it but some of my colleagues put disclaimers on slides. I sometimes do a 'if anyone has been affected' type statement, like on the TV, at the end of lectures. I guess I feel pressure to say, 'support is available', it's kind of good practice. But it's back covering. I worry about questioning the narrative of trauma, but my students need to think about this, they might become mental health nurses! Perhaps it's my own lack of confidence?"

Part of the 'culture' was both an anxiety about whether managers and colleagues would defend you if you discussed a controversial topic, but this was also related to concerns about the 'student body'.

Law lecturer James explained that his colleague, Jim, "says lecturers are now scared of students. Some of them leave their doors open when they have meetings with individual students". James was animate about this. Referring to Agent Smith, the main antagonist in the Matrix film trilogy who can enter anybody within the Matrix and turn them into the enemy, James asserted, "I think of every student as a potential Mr. Smith. You censor yourself with your students, of course you do". James' distrust of his students was replicated and perhaps influenced by his concern about his colleagues. "This environment is not an environment of trust, where you can trust colleagues. They watch every word you say, so I have nothing to do with them". For James, his experiences within the university were situated in the "neoliberal, no such thing as society world. We're all fragmented. Individuals".

Christine's university encouraged students to use a specific webpage where you can anonymously report problematic incidents or events related to Covid-19 and issues of equality, diversity and offence. "It's more the culture it creates," she noted, "it distracts. Existing policies could be used. I guess I just don't like the idea of ratting on other people anonymously, even if it's well meant. Especially if the university then feels it has to do something [such as] investigate. It's not a healthy environment".

Malcolm was concerned that, "universities should embrace people like [Jordan] Peterson. You want academics to challenge everything but that's not what's happening". Media Studies lecturer, Neve, who had been critical of certain transgender policies, explained that in a meeting with human resources, "they explained that I had a pastoral role, and if any student felt that they couldn't approach me about a harassment issue, then I was in breach of contract. They didn't do anything. Just making me 'aware'. I mean they accepted I wouldn't discriminate, and I'd do my job but if a student wouldn't approach me because of something I said, that's it. Breach of contract, because of a feeling. What can you do with that?"

Neve, in a partial defense of her university, explains that, "I suspect lots of complaints, they bat back, but it's partly self-preservation. They worry if the issue becomes an issue they'll be seen as partly responsible. It's managerial. They'd rather controversies just went away".

Christopher was concerned about the perceived need to be or seen to be sympathetic to the experiences of students. "If I want to look at issues in the news, like sectarianism, and want to discuss the myth of sectarianism. Will this mean I can be said to be unsympathetic if someone in the class has experienced sectarianism. Am I unsympathetic to the experience? 
Does it mean we can't challenge the equalities framework-the legal and political framework. Seems very damaging to $\mathrm{me}^{\prime \prime}$.

\subsection{Day to Day}

Despite many of the academics noting that academic freedom or the lack of it was not a constant concern at work, there were, nevertheless, a number of concerns raised about aspects of day-to-day work that did appear to impinge upon this freedom.

Module handbooks or descriptors, according to Paul, were, "weighed down with so much other stuff, on diversity policies, safety and ethical issues, disability and discrimination policies, and so much stuff on 'types of learning'. We've got a ten-page document about how to write a module handbook. It mentions 'learning' about fifty times, explaining how to be 'inclusive' and 'accessible' to diverse needs and spells out that this is legal. It's like a contract or a legal document, [it] talks about data protection issues and resources being used legally, all to ensure the correct learning experience". Paul concluded by noting that, "it's in every module. And then at the end, there's your stuff, your teaching material, the actual course itself, hidden away. It's deprioritising the academic voice. There's so much guff, the core content is tiny, lectures are virtually invisible. The message the students get is that academic content is small. I doubt they read it but it's a symbolic form of marginalising the importance of academic significance".

Neve noted a similar problem in terms of module descriptors and talked about the, "Academic standards people, people who go over and over new descriptors. There's loads of them employed. Just paperwork. It's supposed to make you accountable. But they don't really care".

Other concerns were raised about the pressure of student feedback and with lower expectations on students to cope with work. Christine and James both raised concerns about management telling them they were being too "domineering" when marking. Both were questioned about student feedback where the lecturers were accused of asserting a "right answer" to certain questions. Stephanie felt that "student feedback is a powerful thing". Carol felt that feedback was "generally okay but there is a culture about how to package it a certain way". She continued, "There's an underestimation of what students can take. Tough love perhaps, as a means of helping them grow-sometimes-too low an expectation of what students can handle". Christine thought that, "It's a bit of a pain, some students can't work in groups or do certain things they'd be expected to in the real world, being allowed off assessments. Students at our place seem to regulate their relationship with the university through their wellbeing. We can't mark for poor grammar for a lot of the students, but I do a bit. We've taken on administrative roles now, pastoral roles, like guidance teachers, we're kind of expected to deal with mental health issues. It seems like this mental health approach is more the relationship between students and our university. I kind of worry about this a bit because it undermines the knowledge content and how you relate to it".

\section{Conclusions}

As we 'go to press', two campaigns have just started to have lecturers 'cancelled'; one aims to sack the supposed anti-Semite Professor David Miller; the other targets the claimed Islamophobe Professor Steven Greer. In the petition against the latter, it is argued that Bristol University must act upon its "policies to protect its students," something that must be "balanced' with "academic freedom". Here the speech quotes around academic freedom are used to question the very idea of academic freedom, something that comes a distant second to the need for universities to do as they claim and protect their students.

Are universities places that, as the UK education secretary Gavin Williamson suggests, should be open to outlandish, provocative or uncomfortable ideas? Moreover, is the ideal of academic freedom promoted in the Declaration of Principles, on academic freedom and tenure, a reality? If not, what are the barriers to this? 
The research here would suggest that there are new limits and restrictions that academics face. These are rarely generated by external forces where overt restrictions are enforced, although we do see this with the example of China. Where there are thought to be direct limits on work, these came in the form of academic journals not publishing certain 'controversial' work, although this cannot be proven to be the case. The Prevent Strategy and the Equalities Act 2010 could be seen as external restrictions, although nobody here mentioned Prevent. The equalities framework on the other hand was mentioned by a number of the interviewees, and this framework of engaging with the idea of being 'offended', often with reference to 'protected characteristics', does appear to be of some significance [51].

University equality and diversity policies discuss the need to ensure 'dignity and respect', something that is related to concerns about 'harassment and bullying'. Many universities attempt to deal with these problems through "mandatory diversity awareness training"; but what if dignity and respect is understood to relate to ideas or even attitudes of lecturers? Does this create a crossover of diversity-based issues with a human resource management of student wellbeing?

Controversial ideas and issues were important in terms of the potential for staff to be or to feel that they had limits placed upon them or where they felt they should limit themselves. However, this is unlike the Chinese example, where the Chinese Government is looking at particular ideas that are seen as harmful to the state. Here, in the UK, it is the perceived harm to the student that appears to raise most concerns and potentially limit the freedom of academics to use their own judgement in their day-to-day activities. Any idea that is understood to make students feel 'uncomfortable' or 'excluded' becomes possible grounds for concern and possibly even administrative and management intervention. More generally, it is not simply that certain ideas are problematised but certain academic behaviours are also labelled as being 'unsympathetic' or 'domineering' and are regulated in terms of marking, feedback or expectations of correct lecturing practices.

Although some of those interviewed talked about being 'scared' of students, the term scared seems, at times, to be too extreme, and in general, it would be more accurate to talk about a low-level form of anxiety or unsureness amongst the lecturers. This is related to particular issues, like racism or transgender questions that impacted on lecturers in terms of self-censoring with students, and also to a nervousness with regard to both management and fellow staff member not 'having your back'.

A nervousness also related, for some, with what was seen as the human resources management of 'diversity and equality' issues within the wellbeing framework. Here, as Ecclestone and Hayes have observed, we find a more therapeutic form of management, where the emotional wellbeing of students is understood to be threatened by lecturers whose ideas are seen to be lacking 'respect' or threatening the 'dignity' and therefore the wellbeing of students.

The wellbeing framework, and the need to protect vulnerable students, in this respect, appears to be a significant factor that impacts academic freedom. Nevertheless, it is rare for this to come in the form of an overt or directed challenge to individual lecturers, although this appears to be increasing, and high-profile cases help to create a climate of anxiety. More generally, we find a form of cultural filtering, a consciousness of appropriate behaviour, assisted by a symbolic squeezing out of the knowledge framework by a myriad of procedures and 'correct' forms of learning, for instance when writing module handbooks, marking, giving feedback and in some cases when giving lectures.

Rather than the use of overt force, here we find a 'softer' form of limits, as the guidance of knowledge is supplemented and to some degree usurped by the need to become wellbeing monitors. This, to some extent, can be described as a form of walking on egg-shells, where an unsureness of openness about certain issues with students and with colleagues and management coalesces with new 'respectful' ways to relate to student wellbeing. The result is that day-to-day aspects of work have become framed less through professional judgement of what is best for education and the development of knowledge 
and more with reference to what is 'appropriate' and 'inclusive' and 'supportive' of the 'student experience' and their emotional wellbeing.

Within this climate, regardless of what Gavin Williamson says, making students feel 'uncomfortable' can be problematic. Concerns about student wellbeing can limit what issues and ideas lecturers engage with. Indeed, making students feel uncomfortable is antithetical to an approach that engages with the student body through the prism of vulnerability. This is particularly problematic, giving the potential pedagogical benefits of challenging students' perspectives, even when this is potentially awkward or unpleasant for the student. In this respect, where universities engage with students as vulnerable, we find a new form of pressure or cultural filtering. Consequently, the very practices that are understood to benefit the wellbeing of the student may well act to prevent students from really learning.

A final observation with regard to the pursuit of truth and academic freedom: The ideal of academic freedom encourages an open-ended, experimental and risk-taking approach to university education and research that results in an externally oriented approach to knowledge that is open to criticism. Today, the culture of universities appears to be far more risk averse, more closed to certain questions and even behaviours, something that is more introspective-inner rather than externally oriented-increasingly concerned with the inner-self, the emotional wellbeing of students and with the therapeutic management of the student experience. Rather than encouraging a spirit of discovery, this approach encourages the opposite (concealment) where risks are there to be avoided or managed rather than pushed and explored. If the vulnerable student becomes central to 'good practices' within universities, freedom for academics, in more and more areas of their work will become increasingly problematic. Indeed, academic freedom becomes a problem, a risk, a source of potential anxiety for students, managers and lecturers-academic freedom becomes antithetical to the 'good' university.

Funding: This research received no external funding.

Institutional Review Board Statement: This research was conducted within the following Abertay University framework where, 'Members of the University have a collective responsibility to protect the good names of their colleagues and the institution by ensuring that their own research adheres to the principles of good research conduct and that they promote good research practice within the institution's research community'. The study was conducted according to the guidelines of the Declaration of Helsinki, and approved by the Ethics Committee of Abertay University, approved January 2021.

Informed Consent Statement: Informed consent was obtained from all subjects involved in the study.

Data Availability Statement: The data from the research was recorded in handwritten form and as such avoids the need for online data protection.

Conflicts of Interest: The author declares no conflict of interest.

\section{Appendix A. American Association of University Professors 1915 Declaration of Principles}

The lay public is under no compulsion to accept or to act upon the opinions of the scientific experts whom, through the universities, it employs. But it is highly needful, in the interest of society at large, that what purport to be the conclusions of men trained for, and dedicated to, the quest for truth, shall in fact be the conclusions of such men, and not echoes of the opinions of the lay public, or of the individuals who endow or manage universities To the degree that professional scholars, in the formation and promulgation of their opinions, are, or by the character of their tenure appear to be, subject to any motive other than their own scientific conscience and a desire for the respect of their fellow experts, to that degree the university teaching profession is corrupted; its proper influence upon public opinion is diminished and vitiated; and society at large fails to get from its scholars, 
in an unadulterated form, the peculiar and necessary service which it is the office of the professional scholar to furnish. (American Association of University Professors) [52].

\section{Appendix B. Google Ngrams}

Google Ngrams is a database developed from a collection of books from 1500 that allows a search for names or terms within these books. The calculation takes into account the volume of books at any one time so as to provide a map of the relative use of terms over time. Only when there are at least 40 books using the term in any one year does it appear in the graph. Note that Ngrams has been criticised for its lack of accuracy, in part due to its use of optical character recognition that can produce reading errors. Some of the books in Google Ngrams can be accessed via an Ngrams search, allowing for the texts themselves to be studied, thus allowing these terms to be situated and analysed in the context within which they were written. More than one term can be searched within the same graph, allowing a comparison between the use of terms and to demonstrate similarities in usage. For example, a search for vulnerable children and self-esteem shows the greater use of the latter term but a very similar, indeed almost identical graph shape. For a discussion of the use of Ngrams as a research tool see https:/ / firstmonday.org/ojs/index.php/fm/article/ view/5567/5535 (accessed on 29 August 2019).

\section{References}

1. Hayes, D. Academic Freedom and the Diminished Subject. Br. J. Educ. Stud. 2009, 57, 127-145. [CrossRef]

2. Thomas, N.L. The politics of academic freedom. New Dir. High. Educ. 2010, 152, 83-90. [CrossRef]

3. Strossen, N. Hate: Why We Should Resist It with Free Speech, Not Censorship; Oxford University Press: New York, NY, USA, 2018.

4. The Times Newspaper. Available online: https://www.thetimes.co.uk/edition/news/keep-exposing-young-to-ideasthat-provoke-gavin-williamson-tells-universities-tsdwjfh80?fbclid=IwAR1oJ94LnQgHQKr2a6P0uRH8bBijPhKgrus1hz7 PSRALPV9MNFAXQ1ccH2I (accessed on 19 May 2021).

5. Civitas. Academic Freedom in Our Universities: The Best and the Worst. 2020. Available online: https:/ / www.civitas.org.uk/ content/ files / Academic-Freedom-in-Our-Universities.pdf (accessed on 6 June 2021).

6. Knight, M. Governance in Higher Education Corporations: A Consideration of the Constitution Created by the 1992 Act. High. Educ. Q. 2002, 56, 276-286. [CrossRef]

7. Furedi, F. Letter on Liberty: Freedom Is No Illusion. Academy of Ideas. 2020. Available online: https://academyofideas.org.uk/wpcontent/uploads/2020/12/letters-on-liberty-freedom-no-illusion-pdf.pdf (accessed on 12 January 2021).

8. Harcourt, B.E. The collapse of the harm principle. J. Crim. Law Criminol. 1999, 90, 109-194. [CrossRef]

9. Furedi, F. Where Have All the Intellectuals Gone; Continuum: London, UK, 2004.

10. Furedi, F. What's Happened to the University; Routledge: London, UK, 2017.

11. Ecclestone, K. Learning as Therapy. Br. J. Educ. Stud. 2004, 52, 112-137. [CrossRef]

12. Waiton, S. The Vulnerable Subject. Societies 2019, 9, 66. Available online: https://www.mdpi.com/2075-4698/9/3/66 (accessed on 6 June 2021). [CrossRef]

13. Humphey, R.; McCarthy, P. Stress and the Contemporary Student. High. Educ. Q. 1998, 52, 221-242. [CrossRef]

14. Ecclestone, K. Behaviour change policy agendas for 'vulnerable' subjectivities: The dangers of therapeutic governance and its new entrepreneurs. J. Educ. Policy 2017, 32, 48-62. [CrossRef]

15. Heckathorn, D.D. Respondent-Driven Sampling: A New Approach to the Study of Hidden Populations. Soc. Probl. 1997, 44, 174-199. [CrossRef]

16. Pluckrose, H.; Lindsay, J.A. Cynical Theories; Swift: London, UK, 2020.

17. Foucault, M. The Order of Things; Routledge: New York, NY, USA, 2001.

18. Baudrillard, J. In the Shadow of the Silent Majorities; Semiotext(e) Inc.: New York, NY, USA, 1983.

19. Lasch, C. The Revolt of the Elites and the Betrayal of Democracy; W.W. Norton \& Company: New York, NY, USA, 1995.

20. Bloom, A. The Closing of the American Mind; Penguin: New York, NY, USA, 1987.

21. Williams, J. Academic Freedom in an Age of Conformity; Palgrave Macmillan: Hampshire, UK, 2016.

22. Marcuse, H. Eros and Civilisation; Abacus: London, UK, 1972; Volume 23.

23. Walsh, J. The expanding empire of harm. In Proceedings of the Amnesty International Event, Crescent Arts Centre, Belfast, UK, 5 June 2015.

24. Adler, A. What's left?: Hate speech, pornography, and the problem for artistic expression. Calif. Law Rev. 1996, 84, 1499-1572. [CrossRef]

25. Pluckrose, H.; Lindsay, J. A Manifesto against the Enemies of Modernity. 2017. Available online: https://areomagazine.com/20 17/08/22/a-manifesto-against-the-enemies-of-modernity/ (accessed on 22 February 2020). 
26. Huff. The Waste Land-The Burial of the Dead (Part 1 of 2). Video File. 2015. Available online: https://www.youtube.com/ watch? $\mathrm{v}=$ SsmHarT70MY (accessed on 3 February 2021).

27. Laïdi, Z. A World without Meaning: The Crisis of Meaning in International Politics; Routledge: London, UK, 1998.

28. Bauman, Z. Liquid Modernity; Polity Press: Cambridge, UK, 2000.

29. Furedi, F. Culture of Fear; Continuum: London, UK, 1997.

30. Calcutt, A. Arrested Development; Cassell: London, UK, 1998.

31. Heartfield, J. The 'Death of the Subject' Explained; Sheffield Hallam University: Sheffield, UK, 2006.

32. NUS. 2019. Available online: https://www.nusconnect.org.uk/resources/isolation-and-vulnerability-report (accessed on 21 March 2021).

33. NUS. 2020. Available online: https:/ / www.nus.org.uk/articles/nus-response-to-government-s-higher-education-restructuringregime-0c6e (accessed on 23 May 2021).

34. NUS. 2019. Available online: https:/ / www.nus.org.uk/articles/launch-of-nus-student-gambling-research-1586 (accessed on 12 January 2021).

35. UCU. 2015. Available online: https://www.ucu.org.uk/media/7370/The-prevent-duty-guidance-for-branches-Dec-15/pdf/ ucu_preventdutyguidance_dec15.pdf (accessed on 14 February 2021).

36. Home Office. Revised Prevent Duty Guidance: For Scotland. 2019. Available online: https://www.gov.uk/government/ publications/prevent-duty-guidance/revised-prevent-duty-guidance-for-scotland (accessed on 2 April 2021).

37. Police Scotland. 2020. Available online: https:/ / www.scotland.police.uk/about-us/ (accessed on 15 March 2021).

38. Durodie, B. Securitising education to prevent terrorism. Or losing direction? Br. J. Educ. Stud. 2015, 64, 1-15. [CrossRef]

39. Hume, M. Trigger Warning: Is the Fear of Being Offended Killing Free Speech? William Collins: London, UK, 2015.

40. The Guardian Newspaper. Available online: https://www.theguardian.com/books/2014/may/19/us-students-request-triggerwarnings-in-literature (accessed on 13 March 2021).

41. New Yorker. Available online: https://www.newyorker.com/news/news-desk/trouble-teaching-rape-law (accessed on 15 March 2021).

42. The Times Newspaper. Available online: https://www.thetimes.co.uk/article/walk-out-if-you-get-upset-archaeology-studentstold-8zz6bc7t8 (accessed on 22 April 2021).

43. AFAF (Academics for Academic Freedom). Heroes and Zeros. 2021. Available online: https://www.afaf.org.uk/heroes-andzeros / (accessed on 2 March 2021).

44. The Telegraph Newspaper. Available online: https://www.telegraph.co.uk/news/2020/05/03/oxford-university-students-voteblock-ableist-classist-misogynistic/ (accessed on 2 May 2021).

45. UCLA. 2010. Available online: http://academicaffairs.ucsc.edu/events/documents/Microaggressions_Examples_Arial_2014_1 1_12.pdf (accessed on 12 March 2021).

46. Tumblr. Available online: https:/ /itooamoxford.tumblr.com/ (accessed on 12 January 2021).

47. The Spectator. 15 January 2020. Available online: https://www.spectator.co.uk/article/beware-the-university-campusmicroaggression-monitors (accessed on 15 March 2021).

48. Boostrom, R. 'Safe spaces': Reflections on an educational metaphor. Curric. Stud. 1998, 30, 397-408.

49. Bristol, S.U. Safe Space Policy Reform Motion. Available online: https://www.bristolsu.org.uk/resources/safe-space-policyreform-motion-2016 (accessed on 12 May 2020).

50. Ecclestone, K.; Hayes, D. The Dangerous Rise of Therapeutic Education; Routledge: London, UK, 2019.

51. Equalities Act. 2010. Available online: https://www.legislation.gov.uk/ukpga/2010/15/contents (accessed on 12 February 2021).

52. AAUP'S 1915 Declaration of Principles. Available online: https://aaup-ui.org/Documents/Principles/Gen_Dec_Princ.pdf (accessed on 19 July 2021). 